\title{
Blend and Flip for Teaching Communication Skills to Final Year International Computer Science Students
}

\author{
Tom Worthington \\ Research School of Computer Science \\ Australian National University \\ Canberra, Australia \\ tom.worthington@anu.edu.au
}

\begin{abstract}
In addition to technical knowledge, graduates in computing and engineering disciplines are expected to have communication skills, and the ability to undertake lifelong learning. These skills are difficult to acquire using conventional lecture and tutorial based teaching. Final year international graduate computer science students at the Australian National University, College of Engineering and Computer Science, were found to have particular difficulty when asked to write about their learning. In response, lectures were replaced with online exercises, group workshops in a new purpose-built flat floor classroom, and peer-assessed progressive assessment. This approach was trialed with eighty students in 2019. Preliminary results indicate students performed at least as well as with conventional lecture-based instruction.
\end{abstract}

Index Terms - assessment, e-portfolio, classroom, podcast, reflection, STAR-L, video, WIL, Work-Integrated Learning

\section{INTRODUCTION}

In addition to technical knowledge, graduates in computing and engineering disciplines are expected to have communication skills, and the ability to undertake lifelong learning [1]. These skills are difficult to acquire using conventional lecture and tutorial-based teaching. Final year international graduate computer science students at the Australian National University (ANU), College of Engineering and Computer Science, were found to have particular difficulty when asked to write about their learning. In response lectures were replaced with online exercises, group workshops in a new purpose-built flat floor classroom, and peer-assessed progressive assessment.

\section{A. Learning to Reflect}

Towards the end of their degree, computing students at the ANU may undertake a practical project, either as part of a team, or an individual internship [2]. The last assessment task for the practical project is a written exercise to reflect on learning. Reflection is a useful aid to learning and a valuable skill for a professional who is required to undertake lifelong learning. However, computing students have difficulty with this.

International students who are undertaking their studies in a language which is not their first have additional difficulties [3]. ESOL (English speakers of other languages) students have many challenges with technical writing [4]. Computing and engineering students and others in STEM disciplines undertake courses on how to carry out analysis of problems and present evidence. However, they are rarely asked to examine themselves as a subject. The emphasis is on the use of objective language, with the author removed from the work. In addition, students undertaking group projects, or a workplace internship, are working with others on a collectively set goal. It is difficult at the end of this collective work to switch to a solitary reporting activity.

\section{Methodology}

An action research approach was adopted for evaluating the success of changes to course design. Previous work investigated the online options for improving the course [5]. Here, some limited statistical analysis of student results was possible (discussed under Results below), and more are planned (see Future Research). The emphasis is on short term improvements, and a less formal approach is taken than some recent studies [6]- [7].

One recent, very comprehensive, action research based study of course design used a questionnaire survey, interviews, and classroom observations [6]. However, in this case, the quantitative analysis appears to have displaced the reflective aspect of action research. An earlier study of students' generic skills acquisition used a less complex approach with a survey and interviews [7]. However, even in this simplified case, the quantitative analysis appears to have displaced reflection. A qualitative reflective approach has therefore been taken here, with quantitative analysis to follow.

\section{A. Approach to Teaching Reflection}

Possible ways to help the students would be:

- Progressive: Rather than something required at the end of a course, break the preparation up into a series of exercises. In this way, students can be provided with time to reflect, and benefit from formative feedback on their work. However, for the student to work consistently, there has to be an incentive for doing the exercises on time, by making this a condition of course completion, or each a part of the assessment scheme, or both.

An example of what will not work is to ask the student to complete a reflective journal, but not provide feedback or assessment until the end of the course.

- Collective: Students will benefit from peer feedback on their reflections. The student benefits as much from providing feedback, as receiving it. However, students will need assistance in how to provide feedback if this is something they have not had to do before. Also, an incentive, such as making it a requirement, or assessing the feedback, is required. 


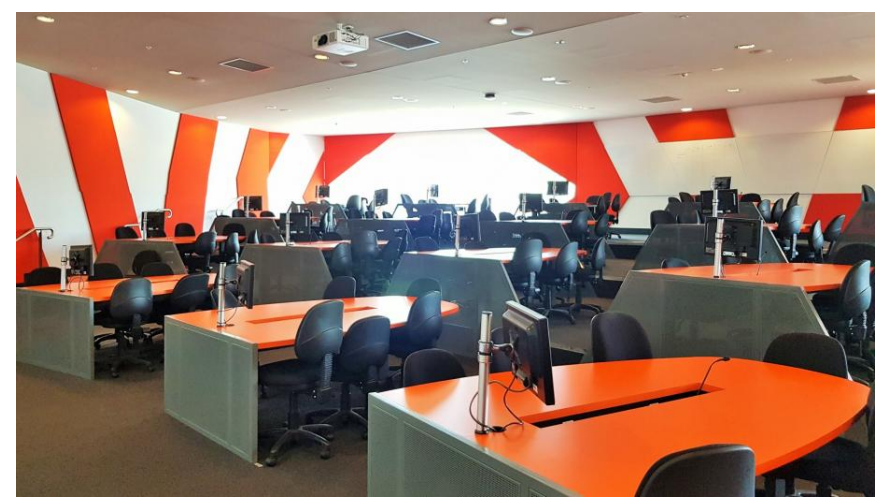

Fig. 1. Tiered seminar room in ANU Sciences Teaching Building.

- Scholarly: Students will benefit from learning a little of why and how a reflective exercise is useful to them. While not attempting to turn every student into a teacher, it would be useful for them to learn a little of the theory behind the reflective exercise. Some of the skills interns learn and report via their portfolio are in the area of Skill management, specifically "learning and development", as defined in the Skills Framework for the Information Age (SFIA) [8]. It would be useful to have this listed in the learning objectives for the course, and then to point out to students this is a skill formally recognized internationally by the computing profession.

- Limited: The value of a reflective portfolio should not be overstated. Claiming the portfolio will be valuable career tool is not likely to be believed by the student, and will not motivate them. Students will have undertaken years of disposable assessment tasks which they complete, and then discard, before moving on to the next. The portfolio exercises can be structured so each builds on the last, but even so, it is too much of a leap of faith to believe any of this will be of use after the end of the course. MacKrell, Mhaisuria, and McDonald [9] investigated the gaps between what a university teaches and what is required by industry. Perhaps identifying these gaps could be an explicit goal of the portfolio exercise for each student. Learning what they have yet to learn might be the most useful outcome of the exercise.

\section{New Flexible Teaching SpaCeS}

Two new teaching buildings opened at ANU in early 2019: a new teaching center and adjacent events building, both by the same architects. These buildings are designed for flexibility of education delivery, but each in a different way. The events building has two high ceiling auditoriums, with seating for five hundred, and two hundred students in tiered theater-style seating, suitable for conventional lectures. The seating is designed to retract, providing large flat floor spaces, which can be used for other teaching styles.

The teaching center has low ceilings, with flat-floor classrooms for thirty, sixty, and one hundred and twenty students, with no tiered seating. Here the flexibility is by multiple electronic screens on different walls, furniture on wheels, and some rooms with retractable walls.

1) Previous Attempts at New Teaching Spaces: The ANU campus has a previous generation of flexible learning space, in the Sciences Teaching Building, designed by Australian architects Lyons and opened in 2014. This flexible learning

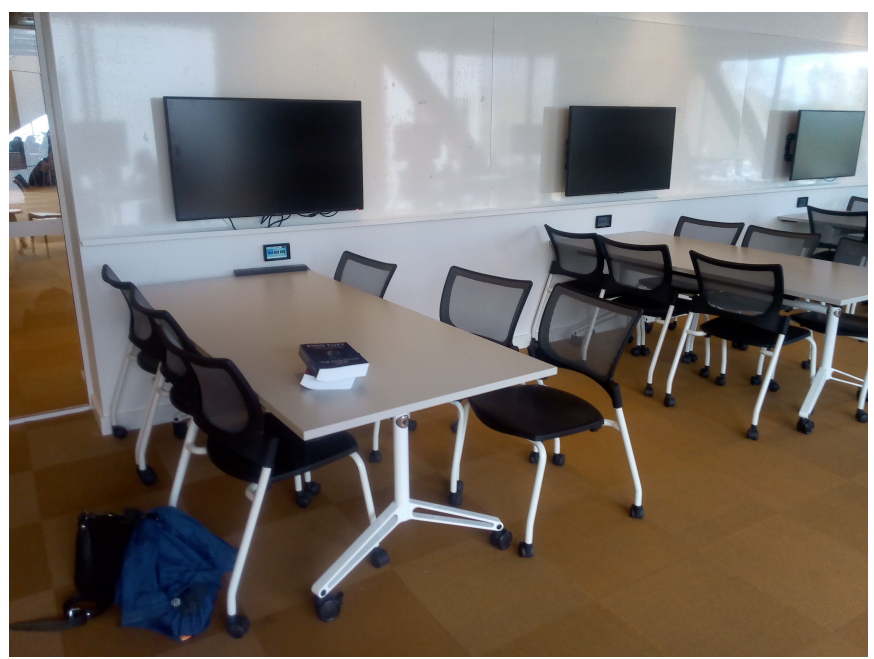

Fig. 2. Flat floor room with wall-mounted screens and tables on wheels at the ANU Marie Reay Teaching Centre.

space accommodates one hundred and fifty students, seated at tables of five. The tables are fixed to the floor, on wide shallow tiers (Figure 1).

The flexible learning space allows for short presentations, with all students focused on a speaker at the front of the room, and then group discussion around each table. However, the room has the disadvantages of both formats: with the low seating density of a flat floor classroom, and the fixed format of a tiered lecture theatre. Because of the depth of the room, to accommodate the tables on tiers, supplementary electronic display screens are provided on each desk, relaying the images from the main display. However, these screens block the view of the presenter for many students. Also, as the cabling for the screens requires the tables to be fixed in place, preventing other room arrangements.

2) Different Room for Different Pedagogy: Two new teaching buildings opened at the Kambri precinct of the ANU campus in February 2019. Both buildings are by Australian architects BVN, with each designed for a different pedagogy. The ANU Cultural Center building has a few large auditoriums, with fixed high density tiered lecture theater seating. This is optimized for conventional lectures, where the students listen to a presenter at the front and watch presentations on a large screen. Interaction is limited to asking a question or using a handheld wireless "clicker" (or mobile device equivalent). Students cannot easily interact with each other, and cannot move the furniture. However, the advantage is that all have a good view of the presenter and screen.

In contrast to the Cultural Center, the ANU Marie Reay Teaching Centre, has smaller rooms, with lower ceilings, movable chairs, and wheeled tables. The seating density is much lower than the cultural center, and with the flat floor it is harder for a student, when seated, to see a presenter on the other side of the room. However, these rooms are intended for interactive group work by students, with formal presentations expected to be kept short, or replaced entirely by online "flipped" content [10]. By having two buildings, each optimized for a specific format, seating capacity can be maintained, with rooms better suited to each a teaching approach.

The room depicted in the Marie Reay Teaching Centre (Figure 2) has electronic screens on the side walls. A desk 


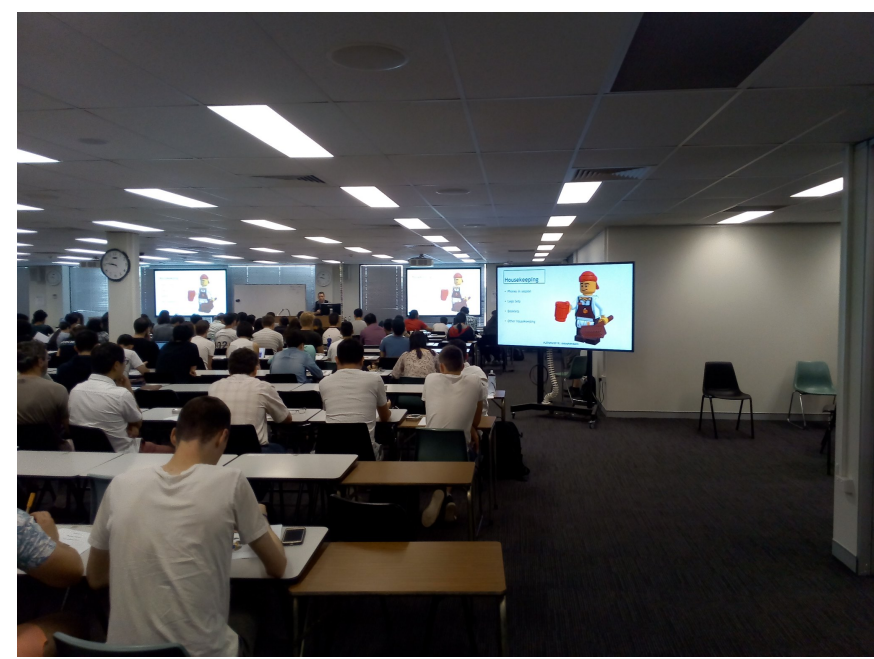

Fig. 3. Computers on Wheels in a large flat floor classroom at the ANU.

can be positioned below each screen. With six students per desk and two rows of three tables, the room can accommodate thirty-six students. As the cabling is in the wall, the screens cannot be moved, but the tables can be rearranged, as required.

Other rooms in the same building do not have the screens for student groups, instead just two large projection screens for presentations, on opposite walls. While not currently deployed at the Marie Reay Teaching Centre, other flat floor classrooms on campus have supplemented the main displays with Computers on Wheels (CoWs) [11]. These screens can each display the work of a group of students, or all shown the presentation from the main room displays (Figure 3 ).

\section{TOP DOWn COURSE DESIGN}

The course design used here parallels the approach taken for the design of the rooms: for flexibility, but with efficiency.

The top-down learning starts with learning objectives, derived from requirements set externally [12]. These set out the skills and knowledge the student is required to have mastered to complete the course. The educational designer may have to refine the objectives provided to make them usable.

For the module on reflective learning, the first draft adapted a skills definition from SFIA skill "Learning and Development" (ETMG):

"Upon completion of this module, students will be able to:

- Determine their own learning needs and possible sources, to develop individual skills for a project and for their career development.

- Identify appropriate accreditation and qualification paths.

- Manage the learning, and evaluate effectiveness through reflection" [8].

The Australian Computer Society uses SFIA for accreditation of university degrees [13]. SFIA is also used by employers defining computing job requirements. Course objectives aligned with SFIA are useful, making course accreditation quicker. This also makes it easier to show employers how skills from a course relate to real-world requirements.

However, it can be difficult to retrofit external learning objectives into an existing course, which is not aligned with
SFIA. After an attempt to use SFIA, this was replaced with the objectives drawn from the existing course description:

"Learn any specific technical skills required by their topic, and apply them to project work. Apply and deepen skills in oral and written communication, and apply these in a project context" [14].

\section{A. Aligning Assessment with Leaning}

Top-down development implies that after the learning objectives are set, the assessment tasks are next defined. However, the course had been run previously with a capstone assessment task. Rather than make too many changes, the capstone was retained, and new small supplementary tasks added leading up to it.

Masters of Computing students previously had difficulty with the capstone. The optimal solution would have been to break the assignment into components, worked on progressively. However, the domestic students of a parallel course were undertaking the same capstone task. Students from the different cohorts are in the same tutorial with a shared tutor. Retaining the same final task for all students was felt to be less confusing.

The solution chose was to halve the marks allocated to the final assessment task and then distribute these to small preparatory exercises. The small exercises are automatically marked multiple choice quizzes, and peer-assessed short written tasks. Retaining the tutor assessed final task provided a level of reassurance for staff who were skeptical as to the reliability of automated and peer assessment.

\section{B. Blended Learning in Chunks}

Learning design takes time. Design of the reflective learning module started in November 2018. At that time completion of new flat-floor classrooms was not certain in time for February 2019 commencement. The week before the semester start date construction equipment was still in place at the site. The equipment was removed the following week and the building was ready with classrooms for the start of semester. However, in late 2018 this could not be assumed and so a conservative approach to blended course design was used, with blended learning chunks:

"The term 'blended learning' usually refers to a mix of conventional face-to-face elements combined with on-line elements. However, this is at too general a level for in-depth analysis of the learning design, while the term 'blend' perhaps suggests too homogeneous a mix: in practice, the mix is more 'lumpy', more a chunky fruit salad than a blended smoothie. At one extreme it is becoming routine for campus-based virtual learning environments (VLEs) to be used to provide additional notes and materials supporting conventional lectures" [15].

The design for the reflective module is a distance education course, with face-to-face workshops inserted, to make it blended. The Moodle Learning Management System was used (LMS) for delivering course notes to the students (and tutors), videos, and podcasts. Announcements to all students and messages to individuals is via the LMS. Smaller items of assessment are provided by the quiz and forum modules of Moodle. The Moodle workshop module is used for large assignments. 
1) Standardized Workshop Format: All face-to-face workshops had the same simple format. This was done to make it simpler for students to follow. Also, it was uncertain if the new classroom would be available, so a conventional lecture theater might need to be used, requiring a change of format. The workshop schedule devised was:

- Announcements: While the room is configured (a requirement in a flexible classroom), announcements can be made.

- General Questions: Before staring on the workshop content, students can ask about any administrative matters, clarification of content, or assessment requirements.

- Forum Questions: Students discuss the answers they posted online, in table groups. Volunteers then present the results of the table discussion to the whole room.

- Master Class for Assignment: As with the forum questions, students first discuss issues with the forthcoming assignment in table groups, then room-wide. Volunteers put drafts of their work on the screen for room-wide feedback.

- Wrap-up: Time is provided at the end of the workshop for concluding remarks and questions.

Using the same format for all workshops allows instructors and participants to become comfortable with approach. Also valuable time is not wasted in class on explanations of what the students are to do.

\section{Chunky Online Learning}

Previously the mix of classroom and online learning was characterized as chunky, that is without the two formats finely inter-meshed. The student is provided with just two packages, both of two weeks duration. Each segment provides discussion questions, one quiz, notes, suggested readings, plus instructions for an assignment. This is laid out in an e-book, like the chapter of a conventional textbook, and the student can run through it in the order presented, over the two weeks. However, the LMS does not impose any timing, ordering, or sequencing on the student: they can study the material in any order at any time in the two weeks.

The use of large online chunks contrasts with tightly scripted learning modules. The tightly scripted approach gives the student a screen-full of text, and a video, then an automated quiz, before moving to the next screen. This requires careful design and testing, much like a computer program, if it is not to frustrate students. Also, this tightly scripted approach requires a responsive and reliable computing platform. In contrast, the chunky approach can tolerate errors in the course design and can be used offline.

\section{Use of a Learning Management System}

The Moodle Learning Management System was used for delivery of learning materials, communication from instructor to the class, to individual students and for assessment. A reading budget was set to ensure students were not asked to read too much. This assumes 80 words per minute reading speed, typical for a student being instructed in English, with this as not their first language, having a 6.5 IELTS score [16]. The course materials include notes in the form of an e-book, and videos with computer generated speech. These materials have been made freely available online, under a Creative Commons Licence [17].

\section{Results of the Learning Module}

The learning module was run with 80 masters of computing students in early 2019. Of these 78 completed the module. The average grade was $67 \%$, and 9.63 standard deviations. This was very close to the overall results for the previous year's cohort of students, with an average of $69 \%$, and 8.37 standard deviations. The latter is for a complete semester course, not just this one learning module. Overall, the student's peer assessment resulting in the same ranking of students as instructor assessment. However, students tended to give high performing students higher grades than instructors, and lower performing students lower grades. Ways to adjust for this are discussed in improvements below.

\section{COURSE IMPROVEMENTS CONSIDERED}

\section{A. Reduce the number of forum posts}

- One question per forum: Currently two questions are asked per forum. This results in a large number of postings for students to read. One should be sufficient to keep students engaged.

- Reduce posting rate: Approximately one-quarter of students left it until the just before the deadline to make all their forum posts. The forum could be set to allow only one post per day, requiring them to spread out their posts.

- Use tutorial cohorts: Having 78 students in one forum resulted in an excessive number of postings for students to read. Dividing students into groups of about 24 (such as groups used for tutorials) would make this more manageable.

\section{B. Change Marking Scheme}

- Fewer marks for early assignments: The first assignment is a practice run for the final exercise, but carries the same marks. The first assignment could have reduced marks and the second, increased.

- Increase the number of peer reviews on assignment: The Moodle workshop algorithm requires at least three peer reviews of each assignment to assess the quality. Students were asked to do three each, but ten percent failed to do any. Ask each student to do four reviews would provide a suitable margin. Also, the mark allocated for conducting the peer review could be increased (from $10 \%$ of the assignment to $25 \%$ ), to provide an incentive, and better reflect the work required.

- Increase instructor weighting for assignment marking: By default, an instructor's assessment of an assignment counts the same as a student's peer review. However, where the students have marked too high, or (more rarely) too low, more adjustment is needed. So set the weighting to four by instructors. That is, the mark from an instructor will count the same as four students.

- Simplified scale for small assessment items: It can be difficult for peers (and even instructors) to grade on the seven-point scale used. So for small exercises, a simpler three-point scale could be used: below expectation, at expectation, above expectation, as used in [8].

- Have small assessment items contribute only up to a medium-range grade: This technique has been used at ANU previously, to ensure that students can't get a high grade, just from the small exercises [18]. To ensure 
students actually do the small tasks, require them to get $50 \%$ for the total of these, to pass the course.

\section{FUTURE RESEARCH}

The aim of this work was to deliver a usable unit of instruction for students, rather than conduct formal research. What has been implemented reflects a social constructionist approach to scaffolded peer learning [19].

The preliminary results indicate that flipped blended approach with peer assessment produces results comparable with conventional lectures and instructor assessment. The University's standard student feedback survey has been distributed to students, along with a separate questionnaire to asses views on the new teaching format. These results will be presented in a future paper. A longitudinal study would also be of value. However, it is possible that, as with other studies of conventional, versus technology-assisted learning, the "no significant difference" effect is in play [20]. As teachers, we can only provide an environment for students to learn, and then leave it to them to learn

\section{CONCLUSION}

Final year international graduate computer science students at an Australian university engineering college undertook online exercises, group workshops, and peer-assessed progressive tasks to assist students to learn to write about learning. Formal analysis of results are yet to be completed, but preliminary work indicates the students trialing this approach in 2019 were able to achieve results consistent with the previous class using conventional lectures. These skills are difficult to acquire using conventional lecture and tutorial based teaching. Replacing lectures with online exercises, group workshops, and peer-assessed progressive tasks appears a viable alternative.

\section{REFERENCES}

[1] A. J. Swart and M. Havenga, "Correlating learning outcomes to the graduate attributes of the international engineering alliance in a problem-based learning module," in 2019 IEEE Global Engineering Education Conference (EDUCON). IEEE, 2019, pp. 34-38.

[2] R. Awasthy, S. Flint, and R. Sankaranarayana, "Lifting the constraints-closing the skills gap with authentic student projects," in 2017 IEEE Global Engineering Education Conference (EDUCON). IEEE, 2017, pp. 955-960.

[3] L. Kaktinšs, "Does turnitin support the development of international students' academic integrity?" Ethics and Education, pp. 1-19, 2019.

[4] E. Epaminonda, C. Christou, and A. Michael, "Language expression technicality in technical report writing for technology major non-native students," in 2019 IEEE Global Engineering Education Conference (EDUCON). IEEE, 2019, pp. 1523-1526.

[5] T. Worthington and $\mathrm{H}$. Wu, "Time-shifted learning: Merging synchronous and asynchronous techniques for e-learning," in 2015 10th International Conference on Computer Science \& Education (ICCSE). IEEE, 2015, pp. 434-437.

[6] F. Lu, Z. Liu, and Z. Liu, "Smart phone endowed intelligent teaching for university general education curriculum in china," in 2018 IEEE International Conference on Teaching, Assessment, and Learning for Engineering (TALE). IEEE, 2018, pp. 690-695.

[7] A. Balderas, L. De-La-Fuente-Valentin, M. Ortega-Gomez, J. M. Dodero, and D. Burgos, "Learning management systems activity records for students' assessment of generic skills," IEEE Access, vol. 6, pp. 15958-15 968, 2018.

[8] "Learning and development management etmg," Jul 2017. [Online]. Available: https://www.sfia-online.org/en/framework/sfia7/skills/procurement-management-support/skill-management/learningand-development-management

[9] D. MacKrell, M. Mhaisuria, and C. McDonald, "The skills framework for the information age as a means for investigating work-integrated learning," in 24th Australasian Conference on Information Systems Melbourne, 2013.
[10] H. T. Ingason and G. R. Gudmundsson, "Is the flipped classroom method useful for teaching project management?" Project Management Research and Practice, vol. 5, pp. ID-5375, 2018.

[11] K. Haines and L. Maurice-Takerei, "The impact of new collaborative learning spaces on tertiary teacher practice," Journal of Learning Spaces, vol. 8, no. 2, 2019.

[12] T. Worthington, "Higher education whisperer," Nov 2018. [Online]. Available: https://blog.highereducationwhisperer.com/2018/11/inreflective-portfolio-what-do.html

[13] B. von Konsky, C. Miller, and A. Jones, "The skills framework for the information age: Engaging stakeholders in ict curriculum design," Journal of Information Systems Education, vol. 27, no. 1, pp. 37-50, 2016.

[14] "Computing project course comp8715," 2019. [Online]. Available: https://programsandcourses.anu.edu.au/2019/course/COMP8715

[15] J. Fleck, "Blended learning and learning communities: opportunities and challenges," Journal of Management Development, vol. 31, no. 4, pp. 398-411, 2012.

[16] M. P. McEwan, "Evaluating and enhancing the feedback process: an international college case study," Practice and Evidence of the Scholarship of Teaching and Learning in Higher Education, vol. 7, no. 1, pp. 79-95, 2012.

[17] T. Worthington, "Learning to reflect module version 2.0," Aug 2019. [Online]. Available: https://blog.highereducationwhisperer.com/2019/08/learning-toreflect-module-version-20.html

[18] T. Worthington, "A green computing professional education course online: Designing and delivering a course in ict sustainability using internet and ebooks," in 2012 7th International Conference on Computer Science Education (ICCSE), July 2012, pp. 263-266.

[19] D. Lindley, "Computer professional education using mentored and collaborative online learning," in SEARCC 2007, Proceedings of the South East Asia Regional Computer Conference, 2007, pp. 18-19.

[20] T. Nguyen, "The effectiveness of online learning: Beyond no significant difference and future horizons," MERLOT Journal of Online Learning and Teaching, vol. 11, no. 2, pp. 309-319, 2015. 